\title{
Effect of Dopant Concentration on Structural, Optical and Magnetic Properties of $\mathrm{Zn}_{1-\mathrm{x}} \mathrm{Ni}_{\mathrm{x}} \mathrm{O}$ Nanocomposites
}

\author{
DHARM VEER ${ }^{1}$, RAMMEHARSINGH $^{1}$ and HARISH KUMAR ${ }^{2 *}$ \\ ${ }^{1}$ Department of Physics, Ch. Devi Lal University, Sirsa (Haryana) -125 055, India \\ ${ }^{2}$ Department of Chemistry, Ch. Devi Lal University, Sirsa (Haryana) -125 055, India \\ harimoudgill@gmail.com
}

Received 28 January 2018 / Accepted 8 March 2018

\begin{abstract}
Zn}_{1-\mathrm{x}} \mathrm{Ni}_{\mathrm{x}} \mathrm{O}(\mathrm{x}=0.0,0.2,0.4,0.6)$ nanocomposites were synthesized by co-precipitation method and further annealed at $400{ }^{\circ} \mathrm{C}$. Characterization of nanocomposites was carried out by $\mathrm{x}$-ray diffraction (XRD), Fourier transform infra-red spectrometer (FTIR), UV-Visible spectroscopic, vibrating sample magnetometer (VSM) and transmission electron microscope (TEM) techniques. The structural study confirms that nickel (II) ions replace $\mathrm{Zn}^{2+}$ ions in the $\mathrm{ZnO}$ lattice without changing its Wurtzite structure and secondary phase $(\mathrm{NiO})$ was observed with the increase in nickel concentration $(x \geq 0.4)$. The presence of various functional groups and $\mathrm{M}-\mathrm{M}$ and $\mathrm{M}-\mathrm{O}$ chemical bonding were confirmed by FTIR. The optical properties of $\mathrm{ZnO}$ nanocrystallities with $\mathrm{Ni}$-doping was investigated by UV-Vis absorption spectra which indicates red shift in the absorption band on Ni- doping. The morphology and structural information were obtained by the TEM images which shows hexagonal nanoparticles with average particle size of $15-50 \mathrm{~nm}$. The change in magnetic behavior of $\mathrm{ZnO}$ nanoparticles with varying $\mathrm{Ni}^{2+}$ doping concentration was investigated by VSM.
\end{abstract}

Keywords: Nanocomposites, Spintronics, Magnetic Semiconductors, Transition metals

\section{Introduction}

The oxide semiconductors play an important role in the area of photonic and spintronic. In the field of spintronics, it is essential to develop semiconductors with ferromagnetically polarized carriers at or above room temperature (RT) such that the spin as well as charge carriers can be coupled with an external magnetic field to control the operation of spintronic devices. The idea of spinis helpful in designing devices with higher data processing speed, low power consumption, large integration capacity and better stability. The transition metals doped semiconductors have been the focus of numerous research investigations because of their usual optical properties and promising potential for applications in optoelectronic devices $^{1,2}$. The transition metals $(\mathrm{TM}=\mathrm{Ni}, \mathrm{Cr}, \mathrm{Mn}, \mathrm{Fe}, \mathrm{Co}$ and $\mathrm{Cu})$ doped $\mathrm{ZnO}$ is an exceptional diluted magnetic semiconductors (DMSs) in which the degree of freedom corresponding to spin is added to the charge and it is very attractive nanomaterials used in various electrical, optical and magnetic applications and are believed to be ideal semiconductor 
materials for spintronics. DMSs are non-magnetic semiconductors in which a fraction of host cations are replaced by magnetic ions ${ }^{3,4}$.

The magnetic semiconductors have attracted major attention of the people working in the area of nanotechnology due to their potential applications in photoelectronics, magnetoelectronics and microwave devices ${ }^{5,6}$. The room temperature ferromagnetism has been established in various semiconducting matrixes by the dilute doping of transition metals ions ${ }^{7}$ but the synthesis of room temperature ferromagnetism (RTFM) is still a controversial issue. Wakano et al ${ }^{8}$., reported that Ni-doped $\mathrm{ZnO}$ nanoparticles exhibits superparamagnetic behavior at room temperature, while Yin et al., observed the paramagnetism in Ni-doped $\mathrm{ZnO}$ films ${ }^{9}$. Some authors have observed the RTFM in nanorods, nanowires and films of $\mathrm{Ni}$ - doped $\mathrm{ZnO}$ film.

Some of the researchers tried to synthesize Ni doped $\mathrm{ZnO}$ based DMSs typically in thin films and by different sol-gel reaction routes. Recently, Srinet et al., observed the RTFM in Nidoped $\mathrm{ZnO}$ with low moment by sol-gel route ${ }^{10}$. Liu et al., found the RTFM in Ni-doped ZnO thin filmsprepared by pulsed laser deposition ${ }^{11}$. Satyarthi et al., claimed the coexistence of intrinsic and extrinsic origins of RTFM in Ni implanted $\mathrm{ZnO}$ films ${ }^{12}$. In some studies, it is also mentioned that the nature of FM in Ni-doped $\mathrm{ZnO}$ does not remain intrinsic upon annealing in various environments at high temperature because of segregation of transition metal ions ${ }^{13}$. Singhla $e a^{l 3}$., claimed that the ferromagnetism in the hydrogenated and vacuum annealed $\mathrm{Ni}$ doped $\mathrm{ZnO}$ disappears upon long reheating at very high temperatures i.e., 700 and $800{ }^{\circ} \mathrm{C}$, respectively. Various chemical methods have been investigated to synthesize the nanoparticles of different material of interest. Most of the $\mathrm{ZnO}$ nanocrystals have been synthesized by traditional high temperature solid state methods in which it is very difficult to control the particle properties and also energy consumption. $\mathrm{ZnO}$ nanoparticles can be prepared on a large scale at low cost by simple solution based method such as co-precipitation method.

In continuation to our earlier study ${ }^{14-17}$, in the present work, we have investigated the structural properties in $\mathrm{Ni}$ doped $\mathrm{ZnO}$ nanoparticles prepared by co-precipitation method which is simple and low cost method and it yields a good end product and it is less time consuming. The synthesized samples were characterized by various techniques like XRD, FTIR, TEM, UV-Vis absorbance and VSM.

\section{Experimental}

AR grade $\mathrm{C}_{4} \mathrm{H}_{6} \mathrm{O}_{4} \mathrm{Zn} \cdot 2 \mathrm{H}_{2} \mathrm{O}, \mathrm{NiCl}_{2} \cdot 2 \mathrm{H}_{2} \mathrm{O}$, ethanol and trimethylamine were used for synthesis. The stoichiometric amount of zinc acetate dehydrate and nickel chloride were separately kept under constant stirring using a magnetic stirrer to completely dissolve the precursors for 30 minutes. After that the two precursor solutions were mixed with constant stirring for 30 minutes. Trimethylamine solution was added drop by drop slowly for $45 \mathrm{~min}$ to the reaction mixture. The solution was continuously stirred at $60{ }^{\circ} \mathrm{C}$ for $3.0 \mathrm{~h}$. The white precipitates obtained were filtered and thoroughly washed several times using double distilled water and ethanol to remove the ions possibly remaining in the final product and then dried in an oven at the temperature of $100^{\circ} \mathrm{C}$ for 12 hours. After that precipitates were crushed gently to fine powder form with pestle and mortar. Finally, the samples were annealed at $400{ }^{\circ} \mathrm{C}$ for $4 \mathrm{~h}$. The following reaction mechanism was followed.

$$
\begin{aligned}
&(1-\mathrm{x}) \mathrm{C}_{4} \mathrm{H}_{6} \mathrm{O}_{4} \mathrm{Zn} \cdot 2 \mathrm{H}_{2} \mathrm{O}+\mathrm{x} \mathrm{NiCl}_{2} \cdot 6 \mathrm{H}_{2} \mathrm{O}+2 \mathrm{C}_{2} \mathrm{H}_{5} \mathrm{OH} \\
&\left(\mathrm{C}_{2} \mathrm{H}_{5} \mathrm{O}\right)_{2} \mathrm{Zn}_{1-\mathrm{x}} \mathrm{Ni}_{\mathrm{x}}+2 \mathrm{CH}_{3} \mathrm{COOH}+2 \mathrm{HCl}+8 \mathrm{H}_{2} \mathrm{O} \\
&\left(\mathrm{C}_{2} \mathrm{H}_{5} \mathrm{O}\right)_{2} \mathrm{Zn}_{1-\mathrm{x}} \mathrm{Ni}_{\mathrm{x}}+2 \mathrm{H}_{2} \mathrm{O} \stackrel{\mathrm{H}^{+}}{\longrightarrow} \mathrm{Zn}_{1-\mathrm{x}} \mathrm{Ni}_{\mathrm{x}}(\mathrm{OH})_{2}+2 \mathrm{C}_{2} \mathrm{H}_{5} \mathrm{OH} \\
& \mathrm{Zn}_{1-\mathrm{x}} \mathrm{Ni}_{\mathrm{x}}(\mathrm{OH})_{2} \stackrel{\Delta}{\longrightarrow} \mathrm{Zn}_{1-\mathrm{x}} \mathrm{Ni}_{\mathrm{x}} \mathrm{O}+\mathrm{H}_{2} \mathrm{O}
\end{aligned}
$$


Structural and morphology of the powder samples were determined by x-ray diffraction (XRD) analysis (Panalytical's X'pert Pro using Cu-K $\alpha 1, \lambda=0.151406 \mathrm{~nm}$ radiations) and transmission electron microscopy (TEM) (Tecnai 200KV Fei Electron Optics $\lambda=35 \mathrm{~nm}$ ). The vibrational frequencies of the bonds in the sample were observed using Fourier transform infrared spectrometer (FTIR) (Perkin Elmer-Spectrum RX-IFTIR) in the wavelength range of $400-4000 \mathrm{~cm}^{-1}$ and the optical absorption spectra were recorded at room temperature using UV-Vis spectrometer (Lambda 750 Perkin Elmer) in the wavelength range of 200-800 nm.TGA/DTA studies were carried out by simultaneous thermal analyzer (Perkin Elmer STA 6000, Temperature range 20-995 ${ }^{\circ} \mathrm{C}$ ). The magnetic study is carried out using VSM (Model PAR 155, Range: 0.00001 to 10000 e.m.u.).

\section{Results and Discussion}

In order to study the effect of doping of $\mathrm{NiO}$ in the $\mathrm{ZnO}$ sample, we have prepared the sample of $\mathrm{Zn}_{1-\mathrm{x}} \mathrm{Ni}_{\mathrm{x}} \mathrm{O}$, with $\mathrm{x}=0.0,0.02,0.04$ and 0.06 and characterized by $\mathrm{XRD}, \mathrm{FTIR}$, UV-Visible, TGA/DTA, TEM and VSM techniques.

\section{XRD Study}

Figure 1 shows XRD patterns of $\mathrm{Zn}_{1-\mathrm{x}} \mathrm{Ni}_{\mathrm{x}} \mathrm{O}(\mathrm{x}=0.0,0.02,0.04$ and $0.06 \mathrm{M})$ samples annealed at $400{ }^{\circ} \mathrm{C}$ and the reflection peaks are indexed to Wurtzite hcp structure of $\mathrm{ZnO}$. The nanostructures shows several peaks of (100), (002), (101), (102), (110), (103), (200), (112), (201), (004) and (202) crystal planes, respectively. All these diffraction peaks were matched well with space group P63 mc (No. 186) (JCPDS No. 36-1451). The XRD pattern indicates the formation of hexagonal Wurtzite phase of $\mathrm{ZnO}$ and no secondary phase was found for the lower concentration doping samples $(\mathrm{x}<0.04)$, which indicates that the Ni ions successfully occupies the lattice site rather than interstitial ones. The occupation of the site of $\mathrm{Zn}^{2+}$ in the lattice by the $\mathrm{Ni}^{2+}$ ions may induce a crystal defect, resulting from the difference in ion size between zinc and nickel. Therefore, these defects changes stoichiometry of the $\mathrm{ZnO}$ lattice. Decrease in the peak intensity and increase in full width at half maxima (FWHM) observed in the XRD patterns of the doped samples confirms a decrease in crystalline quality depending on the $\mathrm{Ni}$ content and confirm the incorporation of nickel dopant into the $\mathrm{ZnO}$ Wurtzite lattice as a substitute atom. When $\mathrm{x}$ reaches 0.04 , an additional small diffraction peak correspond to $\mathrm{NiO}$ (200) comes into existence at an angle $2 \theta \sim 42.5^{0}$ for $x=0.04$ which clearly indicates that phase segregation have occurred in the samples. It is observed that intensity of $\mathrm{NiO}$ peak increases sharply and shifts to the lower angle with increasing nickel concentration. This shift corresponds to the strain and replacement of zinc ion by nickel ions. The observed left shift in the NiO diffraction peak from their native place with increasing nickel content is an evident that $\mathrm{NiO}$ is distorted to larger spacing where nickel gets oxidized and incorporated into $\mathrm{ZnO}$ lattice. Therefore, the saturated solubility ${ }^{18-21}$ of $\mathrm{Ni}$ in $\mathrm{ZnO}$ is $4.0 \%$. From Bragg's law

$$
2 d \operatorname{Sin} \theta=n \lambda
$$

Where, $d$ is lattice spacing, $\theta$ is the diffraction angle and $\lambda$ is the incident wavelength $(\lambda=0.154056)$. The lattice parameters (a and $\mathrm{c}$ ) of the samples for hexagonal system ${ }^{22}$ are calculated by using the formula

$$
\frac{1}{d^{2}}=\frac{3}{4}\left(\frac{h^{2}+h k+k^{2}}{a^{2}}\right)+\frac{l^{2}}{c^{2}}
$$

Where, h, k, 1 are miller indices, from Eq. 4 and 5 for $n=1$, we have 


$$
\operatorname{Sin}^{2} \theta=\frac{\lambda^{2}}{4}\left[\frac{4}{3}\left(\frac{h^{2}+h k+k^{2}}{a^{2}}\right)+\frac{l^{2}}{c^{2}}\right]
$$

In order to calculate unknowns a and c, the peak in form (hk0) and (001) should be selected so that a and c are calculated from Eq. 6. On selecting the proper peaks, following expressions are derived for a and $\mathrm{c}$ as

$$
\alpha=\frac{\lambda \sqrt{h^{2}+h k+k^{2}}}{\sqrt{3} \operatorname{Sin} \theta} \text { and }=\frac{\lambda l}{2 \operatorname{Sin} \theta}
$$

Table 1 shows structural characteristics of $\mathrm{Zn}_{1-\mathrm{x}} \mathrm{Ni}_{\mathrm{x}} \mathrm{O}$ nanocomposites. The $\mathrm{Ni}$ doping has reduced the size of the lattice parameters a and $\mathrm{c}$ which is attributed to the ionic size mismatch between $\mathrm{Zn}^{2+}(0.074 \mathrm{~nm})$ and $\mathrm{Ni}^{2+}(0.069 \mathrm{~nm})$. Theoretically, since the ionic radius of $\mathrm{Ni}^{2+}$ is smaller than that of $\mathrm{Zn}^{2+}$, the peak (101) of the $\mathrm{Ni}$-doped $\mathrm{ZnO}$ should move to larger angle slightly when compared to that of the pure $\mathrm{ZnO}$. From the XRD pattern (Figure 1), it can be seen that the peak (101) of the Ni-doped $\mathrm{ZnO}$ slightly shift to higher angle. The shifting of the XRD pattern and corresponding decrease of the lattice parameters suggests that $\mathrm{Ni}^{2+}$ ions are successfully incorporated into the $\mathrm{ZnO}$ lattice at the $\mathrm{Zn}^{2+}$ crystal sites position. The average crystallite size (d) of the nickel doped $\mathrm{ZnO}$ powders were estimated from x-ray line broadening using the Debye-Scherrer's equation:

$$
d=\frac{0.9 \lambda}{\beta \cos \theta}
$$

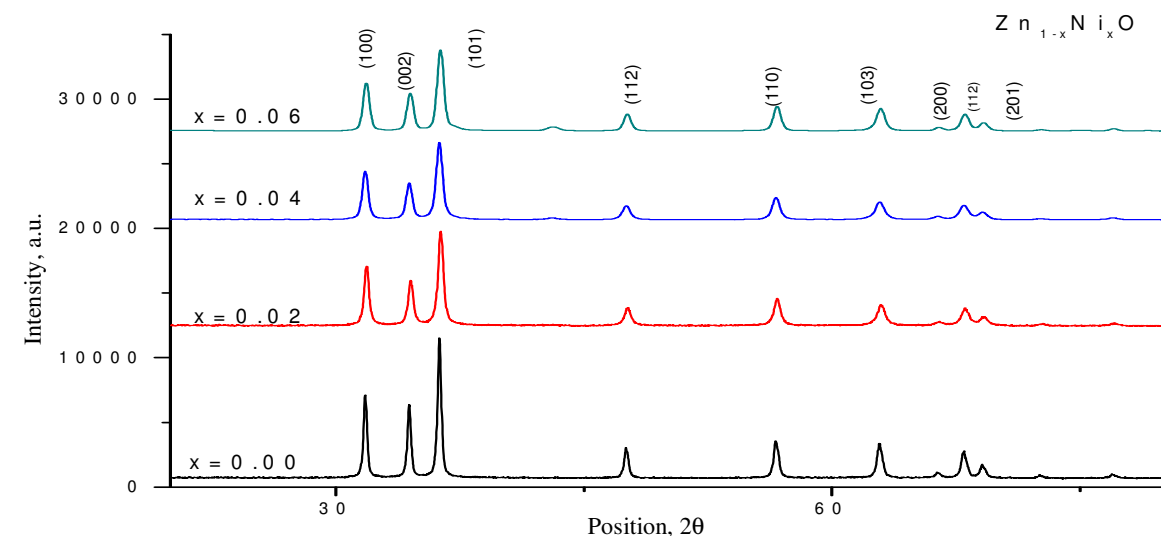

\begin{tabular}{|c|c|c|c|c|c|c|c|}
\hline \multirow{3}{*}{$\begin{array}{l}\text { S. } \\
\text { No. }\end{array}$} & \multirow{3}{*}{$\begin{array}{c}\text { Concentration } \\
\mathrm{x}\end{array}$} & \multicolumn{2}{|c|}{ Lattice parameter } & \multirow{3}{*}{ Strain } & \multirow{3}{*}{$\begin{array}{c}\text { Dislocation } \\
\text { Density }\end{array}$} & \multicolumn{2}{|c|}{$\begin{array}{c}\text { Average } \\
\text { Crystallite Size }\end{array}$} \\
\hline & & $\mathrm{a}=\mathrm{b},(\AA)$ & $\mathrm{c}(\AA)$ & & & D-S & W-H \\
\hline & & hkl(110) & $\mathrm{hkl}(002)$ & & & formula & Plot \\
\hline 1. & 0.1 & 3.2506 & 5.2072 & 0.0036 & $1.19 \times 10^{-3}$ & 27.86 & 28.90 \\
\hline 2. & 0.02 & 3.2494 & 5.1920 & 0.0046 & $1.68 \times 10^{-3}$ & 22.04 & 24.34 \\
\hline 3. & 0.04 & 3.2448 & 5.2044 & 0.0048 & $2.47 \times 10^{-3}$ & 20.19 & 20.11 \\
\hline 4. & 0.06 & 3.2476 & 5.1994 & 0.0058 & $2.69 \times 10^{-3}$ & 19.02 & 19.27 \\
\hline
\end{tabular}

Figure 1. $x$-Ray diffraction pattern of $\mathrm{Zn}_{1-x} \mathrm{Ni}_{\mathrm{x}} \mathrm{O}$ (for $\mathrm{x}=0.0,0.02,0.04$ and 0.06 ) nanocomposites

Table 1. Structural characteristics of $\mathrm{Zn}_{1-\mathrm{x}} \mathrm{Ni}_{\mathrm{x}} \mathrm{O}$ nanocomposites 
The value of dislocation density $(\delta)$ was calculated using the relation, $\delta=1 / \mathrm{d}^{2}$. The crystallite size of the samples decreases with increasing nickel content which is the result of the surface reaction competition ${ }^{23}$. Because the $\mathrm{Ni}-\mathrm{O}$ bond energy is higher than $\mathrm{Zn}-\mathrm{O}$ bond energy, the reaction mobility to raise growth surface will decrease with increasing doping concentration.

In Williamson Hall approach, the line broadening due to finite size of coherent scattering region and the internal stress in the prepared sample is also considered. According to Williamson and Hall, the diffraction line broadening is due to crystallite size and strain contribution. However, x-ray peak profile analysis (XPPA) by $\mathrm{W}-\mathrm{H}$ method is a simplified method which clearly differentiate between size-induced and strain induced peak broadening by considering the peak width as a function of $2 \theta^{24}$. The W-H method does not follow a $1 / \operatorname{Cos} \theta$ dependency as in the Scherrer equation but instead varies with $\tan \theta$. This fundamental difference allows for a separation of reflection broadening when both micro and structural cause's small crystallite size and micro strain occur together. The different approaches assume that size and strain broadening are additive component of the total breadth of a Bragg peak. Scherrer equation and $\varepsilon=\beta_{\mathrm{s}} / 4 \tan \theta$ yield the following equations ${ }^{25}$.

$$
\beta_{h k l}=\beta_{D}+\beta_{s}
$$

Where, $\beta_{\mathrm{D}}$ is due to contribution of crystallite size, $\beta_{\mathrm{s}}$ is due to strain induced broadening and $\beta_{\mathrm{hkl}}$ is the width of the half-maximum intensity of broadening. If we assume that particle size and strain contribution to line broadening are independent of each other and both have a Cauchy-like profile, the observed line width is given by Eq. 9 named as Wilken equation $^{26}$ as:

$$
\beta_{h k l} \operatorname{Cos} \theta=\left(\frac{k \lambda}{D}\right)+4 \varepsilon \operatorname{Sin} \theta
$$

The Eq. 10 assumes that the strain is uniform in all crystallographic directions and named as uniform deformation model (UFM). If $\beta_{\mathrm{hkl}} \operatorname{Cos} \theta$ is plotted as a function of $\operatorname{Sin} \theta$ as shown in Figure 2, then from the linear fit of the data, the crystalline size (d) was estimated from the y-intercept and microstrain $\in$ from the slope of the linear fit.

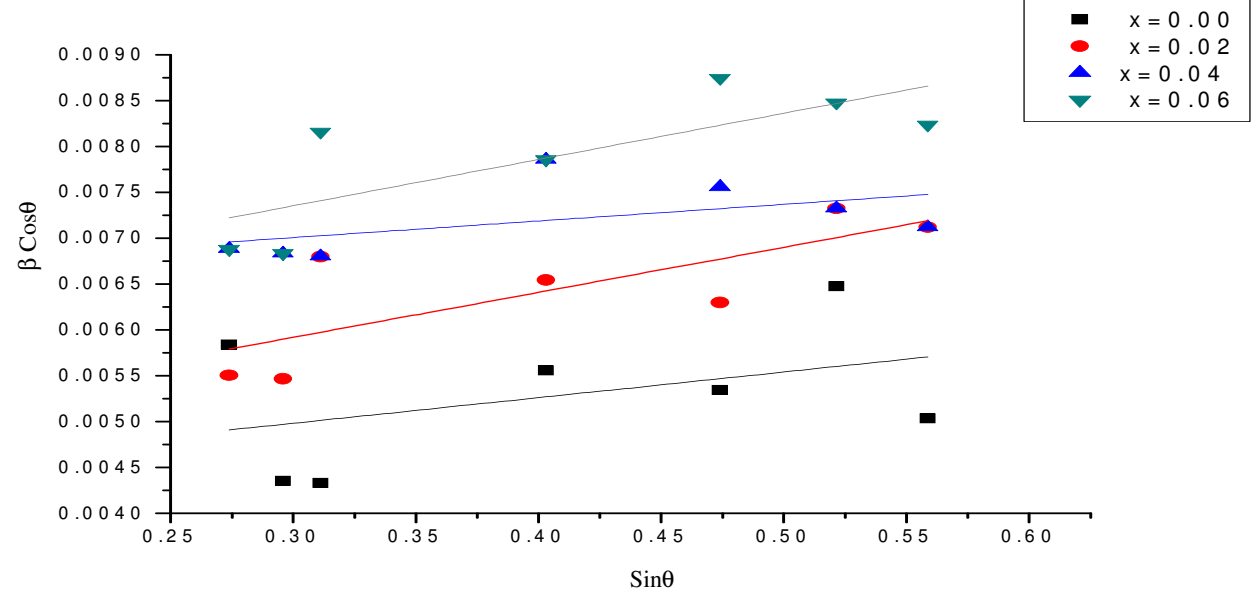

Figure 2. $\mathrm{W}-\mathrm{H}$ plots of $\mathrm{Zn}_{1-\mathrm{x}} \mathrm{Ni}_{\mathrm{x}} \mathrm{O}$ (for $\mathrm{x}=0.0,0.02,0.04$ and 0.06 ) nanocomposites 


\section{FTIR Study}

Figure 3 shows the FTIR spectra of $\mathrm{Zn}_{1-\mathrm{x}} \mathrm{Ni}_{\mathrm{x}} \mathrm{O}(\mathrm{x}=0.0,0.02,0.04,0.06)$ nanocrystals annealed at $400{ }^{\circ} \mathrm{C}$. From the FTIR spectra, the strong vibrational mode observed at $525 \mathrm{~cm}^{-1}$ is assigned to stretching vibration of $\mathrm{ZnO}^{27}$. However, in case of $2.0,4.0$ and $6.0 \%, \mathrm{Ni}$ doped samples, the value of absorption bands were found to be left shifted at 530, 534 and $529 \mathrm{~cm}^{-1}$, respectively. The peaks appearing between 500 and $700 \mathrm{~cm}^{-1}$ were assigned to the metal oxygen (M-O) stretching mode. The FTIR spectrum in the wave number range $<1000$ $\mathrm{cm}^{-1}$ represents the change in the peak position of $\mathrm{ZnO}$ absorption bands reflects that $\mathrm{Zn}-\mathrm{O}$ $\mathrm{Zn}$ network is perturbed by the presence of $\mathrm{Ni}$ in its environment. Therefore, FTIR results also indicate that $\mathrm{Ni}$ is occupying $\mathrm{Zn}$ position in $\mathrm{ZnO}$ matrix as observed in XRD patterns. The vibration mode at wave number 701 and $979 \mathrm{~cm}^{-1}$ were attributed to the vibrations of $\mathrm{Zn}-\mathrm{O}-\mathrm{Ni}$ local bonds and defect states, respectively and associated with $\mathrm{Ni}^{2+}$ occupation at $\mathrm{Zn}^{2+}$ sites. Because the ionic radii mismatch between $\mathrm{Ni}^{2+}$ and $\mathrm{Zn}^{2+}$, intrinsic host lattice defects are activated. The weak absorption band centered at $1369 \mathrm{~cm}^{-1}$ attributed to the stretching vibration of $\mathrm{C}=\mathrm{O}$ and $\mathrm{C}=\mathrm{H}$ groups. The transmission band at 1523 and $1417 \mathrm{~cm}^{-1}$ is due to the carbonyl groups of the carboxylate ions which might remain adsorbed on the surface of $\mathrm{ZnO}$. The absorption peak at $1620 \mathrm{~cm}^{-1}$ corresponds to the bending vibration of the interlayer water molecules ${ }^{28}$. Absorption peaks observed at around $2342 \mathrm{~cm}^{-1}$ are assigned to the $\mathrm{CO}_{2}$ mode which is due to atmospheric $\mathrm{CO}_{2}$ and other transmission band at $2928 \mathrm{~cm}^{-1}$ is assigned to a residual organic component. The broad absorption band at 3495 $\mathrm{cm}^{-1}$ corresponds to the $\mathrm{O}-\mathrm{H}$ stretching vibrations of water present in $\mathrm{ZnO}$. As the concentration of the dopant is increased then the peaks are shifted to left indicating the incorporation of nickel in the $\mathrm{ZnO}$ lattice site.

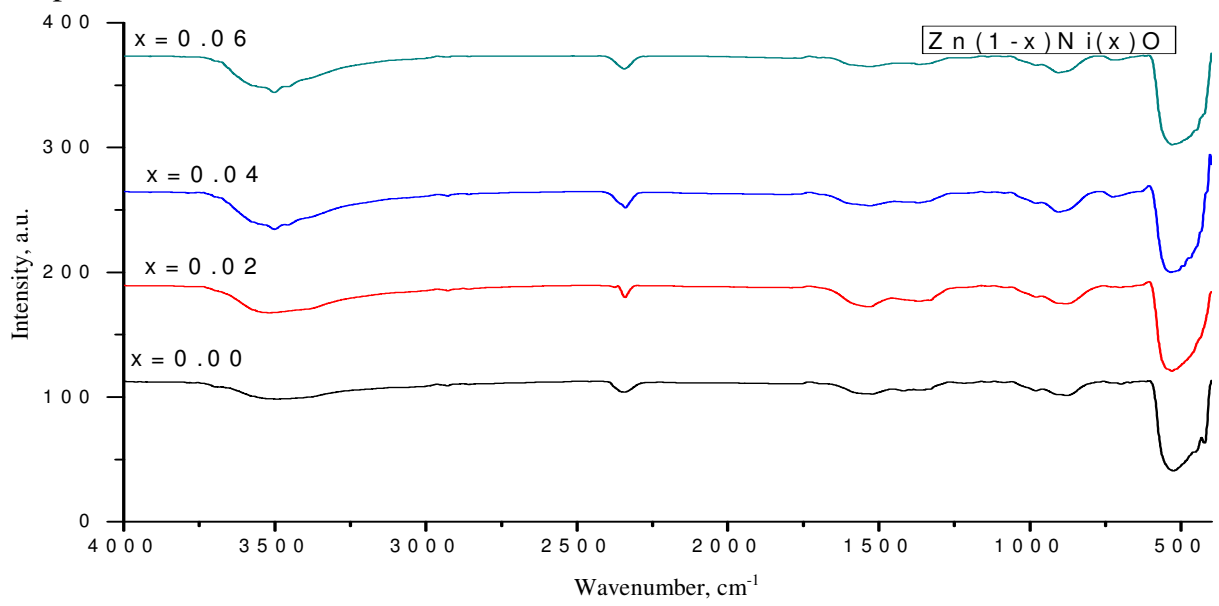

Figure 3. FTIR spectra of $\mathrm{Zn}_{1-\mathrm{x}} \mathrm{Ni}_{\mathrm{x}} \mathrm{O}$ (for $\mathrm{x}=0.0,0.02,0.04$ and 0.06) nanocomposites

\section{UV-Vis Study}

Figure 4 shows UV-Visible spectra of $\mathrm{Zn}_{1-\mathrm{x}} \mathrm{Ni}_{\mathrm{x}} \mathrm{O}$ ( $\left.\mathrm{x}=0.0,0.02,0.04,0.06\right)$ nanocomposites annealed at $400{ }^{\circ} \mathrm{C}$. Pure $\mathrm{ZnO}$ sample shows absorption band edge at $360 \mathrm{~nm}$ and observed band edge shows a shift towards higher wavelength side for the nickel doped sample i.e., at 320,310 and $250 \mathrm{~nm}$. The blue shift of the band edge for the nickel doped sample clearly indicates that $\mathrm{Ni}^{2+}$ ions are incorporated into the $\mathrm{ZnO}$ lattice ${ }^{29-31}$ which confirms the results of XRD and FTIR results. Optical band gap was evaluated using the equation: 


$$
(\alpha h v)^{\mathrm{n}}=\mathrm{A}\left(\mathrm{h} v-\mathrm{E}_{\mathrm{g}}\right)
$$

Where $\alpha=$ absorption coefficient, $h v=$ photon energy, $A=$ constant relative to the material and $n=2$ for direct band gap material or $1 / 2$ for an indirect band gap material. According to the equation, the optical band gap for the absorption peak can be obtained by extrapolating the linear portion of the $(\alpha \mathrm{hv})^{2} v s$. hv curve to zero and the observed energy gaps are 3.4, 3.8, 4.0 and $4.9 \mathrm{eV}$. These indicate that band gap of $\mathrm{ZnO}$ material increases with doping concentration of $\mathrm{Ni}^{2+}$ ions. The increase in the band gap or blue shift can be explained by the Burstein effect. This is the phenomena that the Fermi level merges into the conduction band with the increase of carrier concentration.
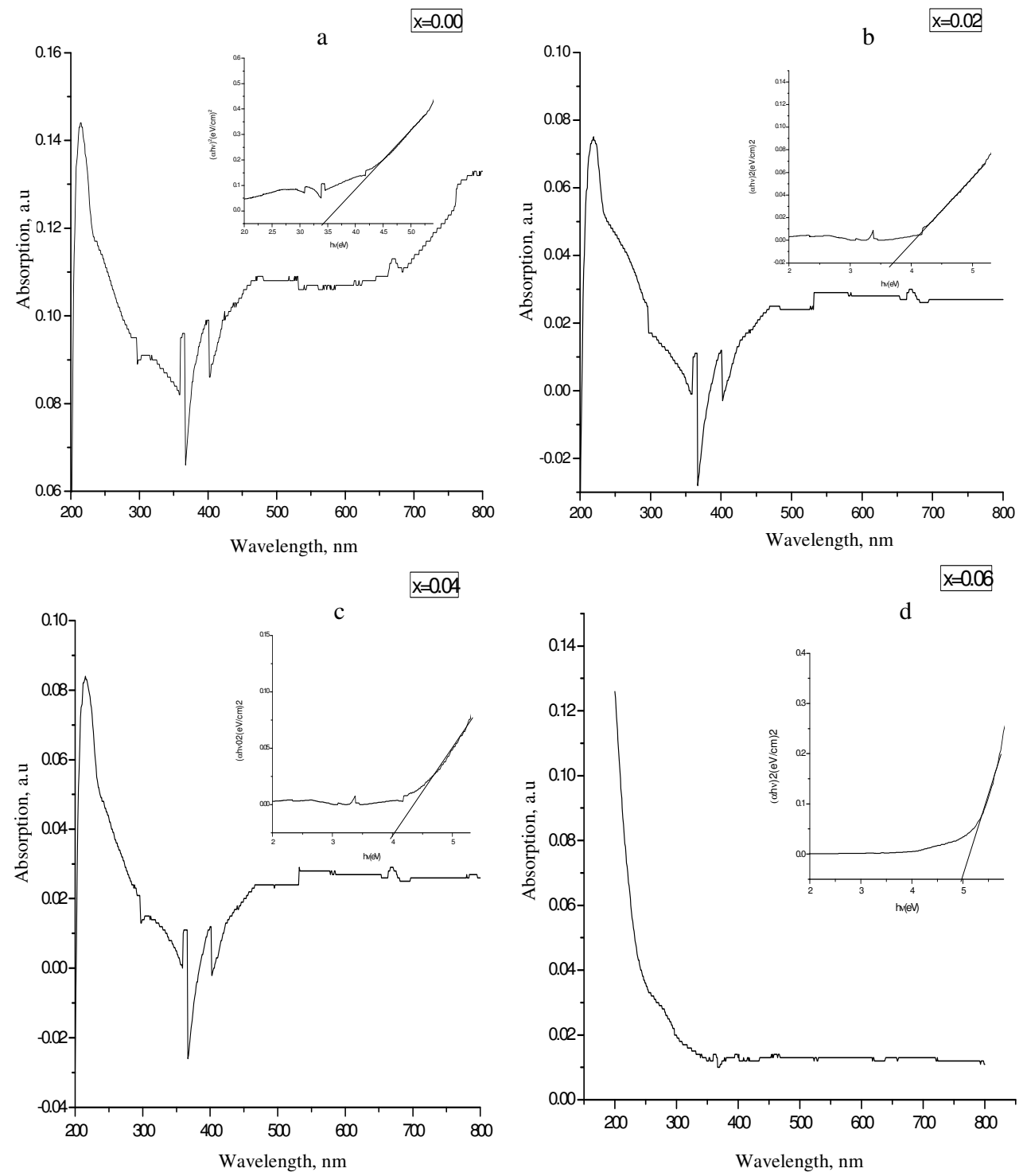

Figure 4. $\mathrm{UV}-\mathrm{V}$ is spectrum of $\mathrm{Zn}_{1-\mathrm{x}} \mathrm{Ni}_{\mathrm{x}} \mathrm{O}$ (for $\mathrm{x}=0.0,0.02,0.04$ and 0.06 ) nanocomposites 


\section{TEM Analysis}

TEM was employed to study the shape and size of nanocrystallites and to confirm the nanocrystalline structure of the prepared samples. Figure 5 shows the TEM images of nanocrystalline nature of undoped and doped $\mathrm{ZnO}$ samples. TEM images of undoped $\mathrm{ZnO}$ showed aggregates of non-uniform solids of different shape and size in the range 17-56 $\mathrm{nm}$ and nickel doped zinc oxide showed aggregates of smooth solids of nearly spherical shape in the range 15-43.0 $\mathrm{nm}$. Different kinds of shapes like irregularly shaped nanoparticles, rectangular and hexagonally shaped nanoparticles are visible for the undoped nanoparticles. However, doped nanoparticles are of regular shapes, mostly spherical and its size is reduced with nickel doping which confirms the XRD results. The micrographs of the prepared samples reveal the compact arrangement of almost homogenous nanoparticles with nearly cubical and quasi spherical shape indicating crystalline nature of the metal. The particle size of the sample is decreased with increasing the concentration of nickel. The images clearly show the agglomeration of nanoparticles which may be attributed to the magnetic dipole interaction between the particles. The particle size determined from TEM is in agreement with XRD measurements. The histograms of the TEM images are shown in Figure 6.

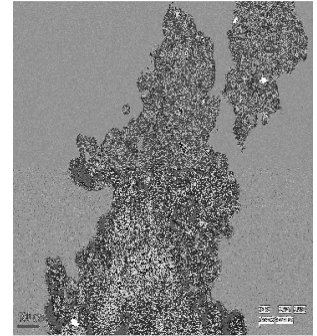

(a)

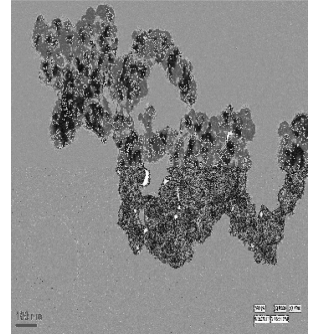

(b)

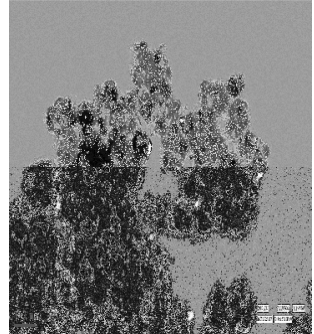

(c)

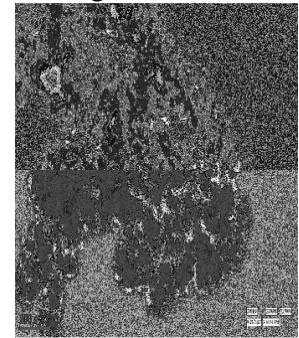

(d)

Figure 5. TEM microgram of $\mathrm{Zn}_{1-\mathrm{x}} \mathrm{Ni}_{\mathrm{x}} \mathrm{O}$ (a) $\mathrm{x}=0.0$, (b) $\mathrm{x}=0.02$, (c) $\mathrm{x}=0.04$, (c) $\mathrm{x}=0.08$ nanocomposites





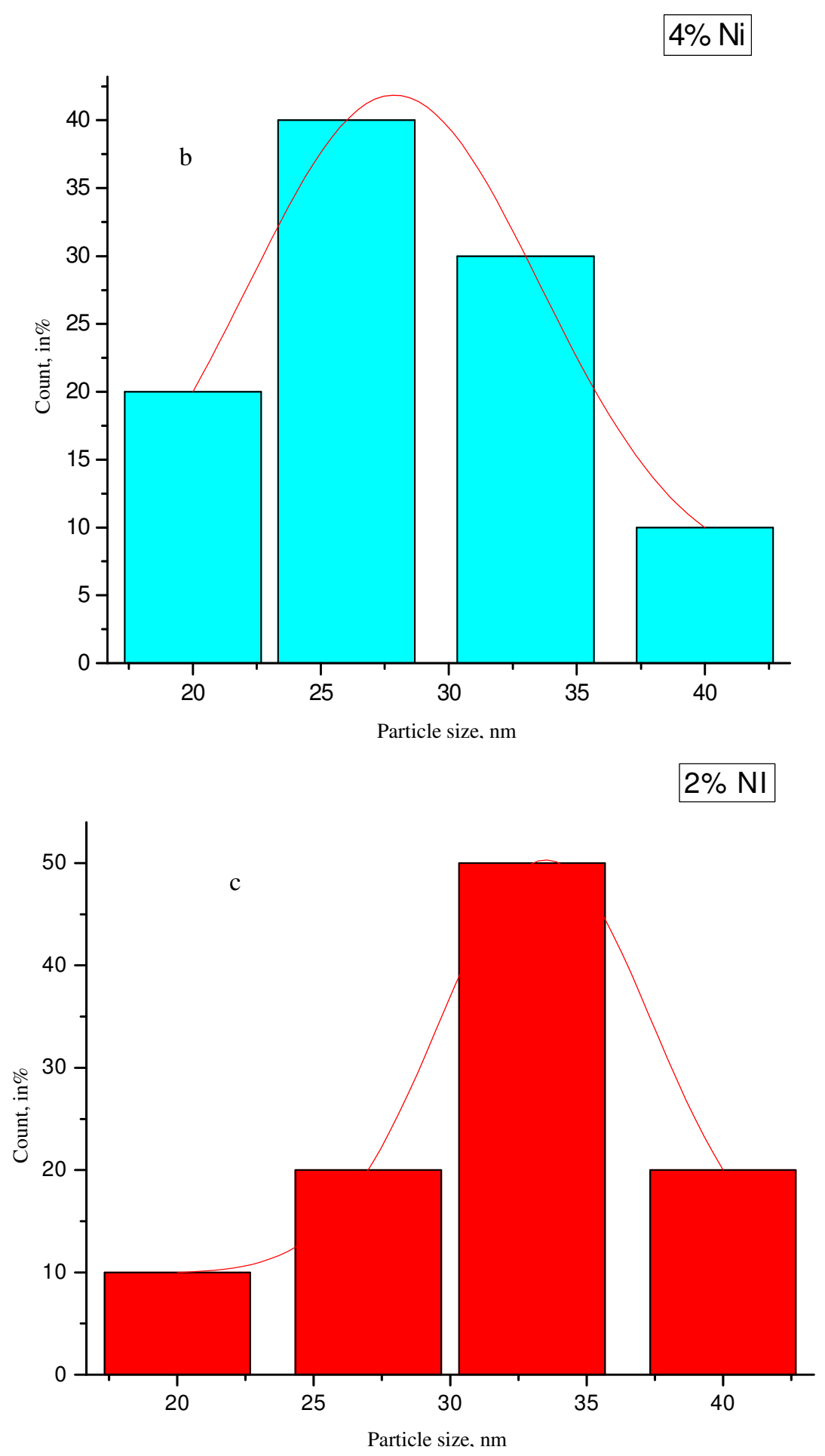


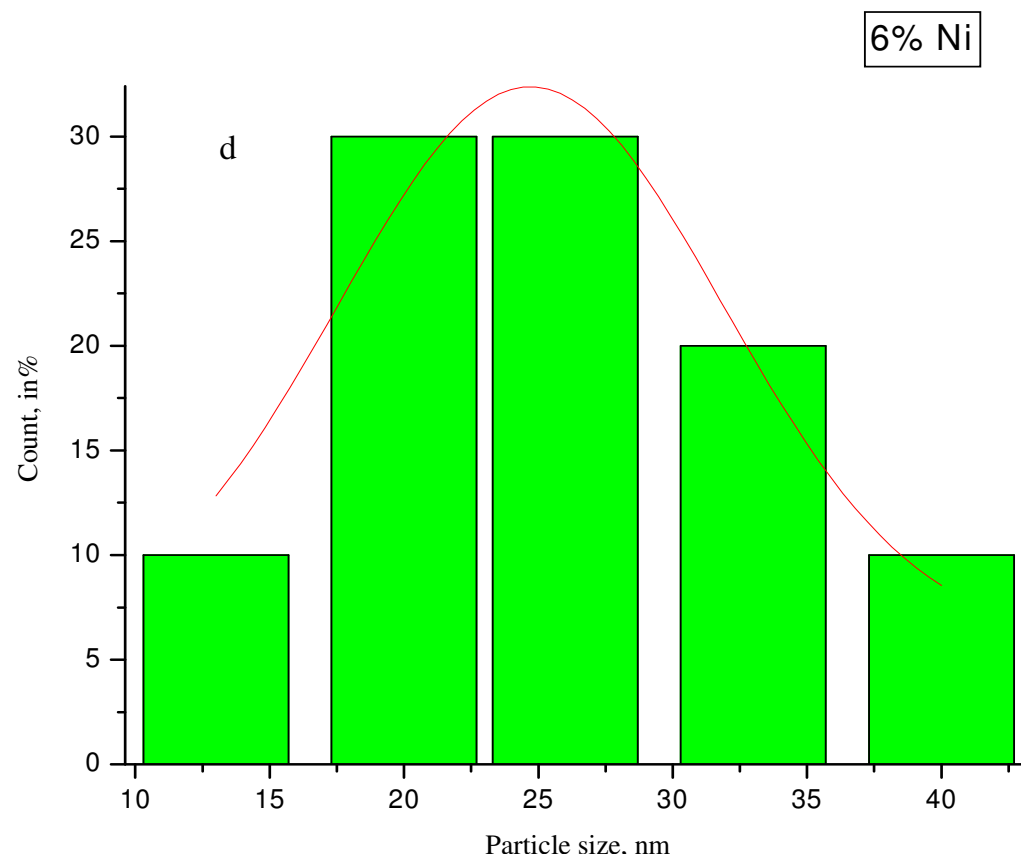

Figure 6. TEM Histogram of $\mathrm{Zn}_{1-\mathrm{x}} \mathrm{Ni}_{\mathrm{x}} \mathrm{O}$ (for $\mathrm{x}=0.0,0.02,0.04$ and 0.06 ) nanocomposites

\section{Vibrating Sample Magnetometer (VSM) Study}

Figure 7 shows the VSM results for $\mathrm{Zn}_{1-\mathrm{x}} \mathrm{Ni}_{\mathrm{x}} \mathrm{O}$ sample at room temperature. The bent natures of the curves clearly exhibits a shallow ferromagnetism in the samples. The parmagnetic component was subtracted from the original data in order to determine the ferromagnetic part. The value of magnetic resonance and coercivity of $\mathrm{Zn}_{1-\mathrm{x}} \mathrm{Ni}_{\mathrm{x}} \mathrm{O}$ samples are shown in Table 2. It can be observed that both coercivity and remanence increases with the addition of $\mathrm{Ni}$ in pure $\mathrm{ZnO}$. Some ferromagnetic behavior observed in $\mathrm{Ni}$ doped $\mathrm{ZnO}$, can be explained due to formation of nanoscale Ni-related secondary phase, such as Ni cluster or $\mathrm{NiO}$. Firstly, the origin from $\mathrm{NiO}$ can be ruled out, as bulk $\mathrm{NiO}$ is antiferromagnetism at room temperature, secondly the existence of metallic $\mathrm{Ni}$ is also an unlikely source of this ferromagnetism because the synthesis of Ni-doped sample is performed in water as well as $\mathrm{OH}^{-}$which can prevent the formation of metallic Ni nanocluster to some extent. Hence, ferromagnetism could be considered as a result of exchange interaction between free delocalized carriers and delocalized $\mathrm{d}$ spins in the $\mathrm{Ni}$ ions ${ }^{32-34}$. In order to study the magnetic behavior of pure and $\mathrm{Ni}$ doped $\mathrm{ZnO}$ nanoparticles as a function of magnetic field at room temperature, the M-H curve (Figure7) confirms that pure and Ni-doped $\mathrm{ZnO}$ nanoparticles show ferromagnetic ordering.

Table 2. Magnetic properties of $\mathrm{Zn}_{1-\mathrm{x}} \mathrm{Ni}_{\mathrm{x}} \mathrm{O}$ (for $\mathrm{x}=0.0,0.02$ and 0.04) nanocomposites

\begin{tabular}{cccc}
\hline $\mathrm{x}$ & Coercivity, Oe & Retentivity, emu/g & $\begin{array}{c}\text { Saturation magnetization } \\
\text { emu/g }\end{array}$ \\
\hline 0.00 & 185 & 0.057 & 0.10 \\
0.02 & 226 & 0.050 & 0.12 \\
0.04 & 97 & 0.064 & 0.18 \\
\hline
\end{tabular}




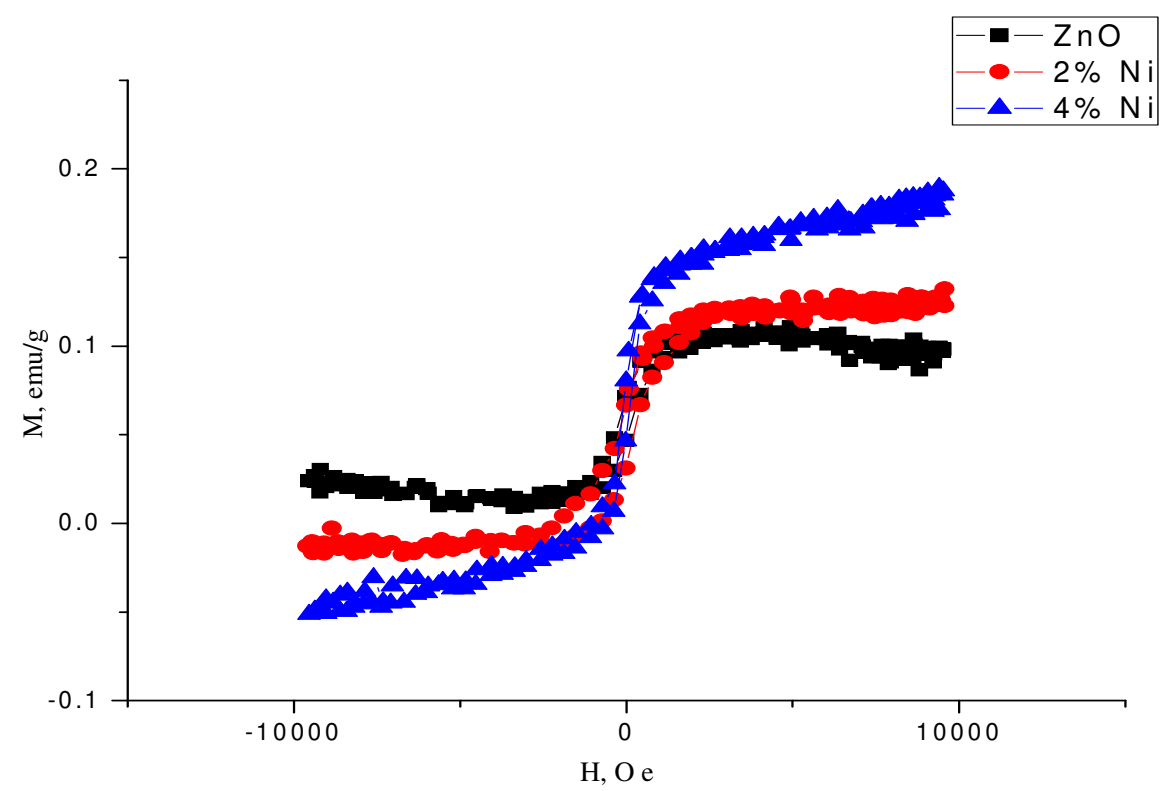

Figure 7. VSM Spectra of $\mathrm{Zn}_{1-\mathrm{x}} \mathrm{Ni}_{\mathrm{x}} \mathrm{O}$ (for $\mathrm{x}=0.0,0.02,0.04$ and 0.06 ) nanocomposites

\section{Conclusions}

Nickel doped $\mathrm{ZnO}$ nanocomposites $\left(\mathrm{Zn}_{1-\mathrm{x}} \mathrm{Ni}_{\mathrm{x}} \mathrm{O}\right)$ have been prepared by co-precipitation method and changes in their structural, optical and magnetic properties as a function of doping concentration were investigated. The nanoparticles of Ni-doped $\mathrm{ZnO}$ continue to have a similar Wurtzite phase as that of undoped $\mathrm{ZnO}$. The XRD pattern indicates that Nidoping cause little or no structural disorder in the $\mathrm{ZnO}$ lattice, while the concentration of dopant was lower than $4 \%$. With increasing $\mathrm{Ni}$ concentration, phase segregation takes place in the sample. The size of the nano particles and lattice constants decreases with increasing the dopant concentration due to mismatch of ionic radii. The FTIR analysis confirms the formation of defect centers in the structure and presence of functional groups and chemical bonding with $\mathrm{Ni}$. The optical band gap of $\mathrm{Zn}_{1-\mathrm{x}} \mathrm{Ni}_{\mathrm{x}} \mathrm{O}$ was calculated from the absorption spectra and it decreases with increase in nickel concentration. The observed red shift in the band edge of the nickel doped $\mathrm{ZnO}$ nanoparticles is due to the increasing sp-d exchange interactions between the band electrons and the localized d-electrons of the $\mathrm{Ni}^{2+}$ ions substituting $\mathrm{Zn}^{2+}$ ions in the doped sample indicating the substitution of $\mathrm{Ni}$ ion into the $\mathrm{Zn}$ site of the $\mathrm{ZnO}$ lattice. The morphology and microstructure of the samples were investigated by TEM which shows that nanoparticles are hexagonal and cubical in shape and the particle size estimated by statistical method is approximately 30, 24, 21 and $18 \mathrm{~nm}$, respectively which were in accordance with the XRD results. Magnetic measurement studies reveals that all $\mathrm{Ni}$ - doped samples shows room temperature ferromagnetism which is attributed to oxygen/Zn vacancies and nickel dopant. The saturation magnetization increases and coercivity of the samples decreases well with increasing nickel doping.

\section{References}

1. Yang H M and Nie S, Mater Chem Phys., 2009, 114(1), 279-282; DOI:10.1016/j.matchemphys.2008.09.017 
2 Saal H, Bredow T and Binnewies M, Phys Chem Phys., 2009, 11, 3201-3209; DOI:10.1039/B901596E

3 Zhung L J, Wu X M, Wu Z F, Yang X M, Chen X M and Chen Q, Mater Chem Phys., 2010, 120(2-3), 480-483; DOI:10.1016/j.matchemphys.2009.11.036

4 Dinesha M L, Jayanna H S, Mohanty S and Ravi S, J Alloys Compd., 2010, 490(1-2), 618-623; DOI:10.1016/j.jallcom.2009.10.120

5 Prinz G A, Science, 1998, 282, 1660-1663; DOI:1126/science.282.5394.1660

6 Jaffe J E, Droubay T C and Chambers S A, J Appl Phys., 2005, 97(7), 073908; DOI:10.1063/1.1868056

7 Prakash R, Song J I, Kumar S and Lee C G, Int J Nanoscience, 2011, 10, 961-965; DOI:10.1142/S0219581X11008721 39

8 Wakano T, Fujimura N, Morinaga Y, Abe N, Ashida A and Ito T, Physica E, 2001,10, 260-264.

9 Yin Z, Chen N, Yang F, Song S, Chai C, Zhong J, Qian H and Ibrahim K, Solid State Commun., 2005, 135(7), 430-433; DOI:10.1016/j.ssc.2005.05.024

10 Srinet G, Kumar R and Sajal V, J Appl Phys., 2013, 114(3), 033912; DOI:10.1063/1.4813868

11 Liu X, Lin F, Sun L, Cheng W, Ma X and Shi W, Appl Phys Lett., 2006, 88(6), 062508; DOI:10.1063/1.2170420

12 Satyarthi P, Ghosh S, Pandey B, Kumar P, Chen C L, Dong C L, Pong W F, Kanji Lal D, Asokan K and Srivastava P, J Appl Phys., 2013, 113(18), 183708; DOI:10.1063/1.4804253

13 Singhal R K, Sharma S C, Kumari P, Kumar S, Xing Y T, Deshpande U P, Shripathi T and Saitovitch E, J Appl Phys., 2011, 109, 063907.

14 Kumar H, Dharam Veer and Dixit R M, Chem Sci Trans., 2018, 7(1), 95-100; DOI:10.7598/cst2018.1462

15 Kumar $\mathrm{H}$ and Manisha, Asian J Chem., 2018, 30(1), 59-62; DOI:10.14233/ajchem.2018.20853

16 Kumar H, Dixit R M and Dharam Veer, Asian J Chem., 2017, 29(11), 1-5.

17 Kumar H and Manisha, Asian J Pharma Clin Res., 2017, 10(9), 206-209; DOI:10.22159/ajpcr.2017.v10i9.19459

18 Li B B, XiuX Q, Zhang R, Tao ZK, Chen L, Xie Z L, Zheng Y D and Xie Z, Mater Sci Semicond Process, 2006, 9(1-3), 141-145; DOI:10.1016/j.mssp.2006.01.074

19 Zhao Jing, Wang Li, Yan Xiaoqin, Yang Ya, Lei Yang, Zhou Jing, Huang Yunhua, Yousong $\mathrm{Gu}$ and Zhang $\mathrm{Y}$, Mat Res Bull., 2011, 46(8), 1207-1210; DOI:10.1016/j.materresbull.2011.04.008

20 Xingyu M, Wei $\mathrm{Z}$ and Youwei D, J Magn Mater., 2008, 320, 1102; DOI:10.1016/j.jmmm.2007.10.022

21 Lupana O, Chowa L, Chaic G, Roldana B, Naitabdia A, Schultea A and Heinricha H, Mater Sci Eng B., 2007, 145(1-3), 57-66; DOI:10.1016/j.mseb.2007.10.004

22 Yu W, Yang L H, Teng X Y, Zhang J C, Zhang L and Fu G S, Appl Phys., 2008, 103, 093901; DOI:10.1063/1.2903524

23 Suryanarayana C, Norton MG X-ray Diffraction: a Practical Approach. Plenum Press Publishing, New York, 1998.

24 Biju V, Sugathan N, Vrinda V and Salini S L, J Mater Sci., 2008, 43, 1175-1179;

DOI:10.1007/s10853-007-2300-8

25 Pandiyarajan T, Karthikeyan B, J Nanopart Res., 2012, 14, 647;

DOI:10.1007/s11051-011-0647-x 
26 Perales-Perez O, Parra-Palomino A, Singhal R, Voyles P M, Zhu Y, Jia W and Tomar M S, Nanotechnology, 2007, 18(31), 315606; DOI:10.1088/09574484/18/31/315606

27 Elilarassi R and Chandrasekaran G, Optoelectronics Lett., 2010. 6(1), 6-10; DOI:10.1007/s11801-010-9236-y

28 Deka S and Joy P A, Chem Mater., 2005, 17(26), 6507-6510; DOI:10.1021/cm051931i

29 Kim K J and Park Y R, Appl Phys Lett., 2002, 81, 1420; DOI:10.1063/1.1501765

30 Samanta K, Dussan S, Katiyar R S and Bhattacharya P, Appl Phys Lett., 2007, 90, 261903; DOI:10.1063/1.2751593

31 Weaklim H A, J Chem Phys., 1962, 36(8), 2117; DOI:10.1063/1.1732840

32 Dianwu W, Mei Y, Zhongbing H, Guangfu Y, Xiaoming L, Yunqing K, Xianfu C and Hui W, J Colloid Interface Sci., 2009, 330(2), 380-385; DOI:10.1016/j.jcis.2008.10.067

33 Koseoglu Y, Durmaz Y C and Yilgin R, Ceramics Internat., 2014, 40(7), 1068510691; DOI:10.1016/j.ceramint.2014.03.053

34 Radovanovic P V and Gamelin D R, Phys Rev Lett., 2003, 91, 157202;

DOI:10.1103/PhysRevLett.91.157202 